PREGLEDNI

ČLANAK

\title{
Is the Dodo bird a Jedi or a Sith? A commentary of efficacy across therapeutic modalities
}

\section{Da li je Ptica Dodo Džedaj ili Sit? Komentar efikasnosti različitih terapijskih modaliteta}

Radomir Belopavlović, Faculty of Philosophy, Novi Sad

Tanja Petrović, Faculty of Philosophy, Novi Sad

Snežana Tovilović, Faculty of Philosophy, Novi Sad

ABSTRACT In this paper we discuss the issue of the Dodo verdict, i.e. the empirically supported notion that different psychotherapeutic modalities have the same outcomes. Firstly, we present the historical background of this notion and link it with the current issues in psychotherapy.

Keywords: Next, we present the pertinent literature which focuses on the similarities and differences Psychotherapy, in outcomes across modalities, as well as elucidate the recognised effective instances in

Efficacy, psychotherapy such as effects of the client, therapist and their interaction. Additionally, we Dodo verdict

SAŽETAK discuss the trends in efficacy research and posit questions about the nature of the theory and practice of psychotherapy. We also provide a critique, elucidate the potential problems and offer different perspectives on the importance and meaning of the Dodo conjecture, concerning both therapeutic and extra - therapeutic consequences and correlates.

Ključne reči:

U ovom radu diskutujemo o pitanju Dodo presude, odnosno empirijski podržane ideje da različiti psihoterapijski modaliteti imaju iste ishode. Prvenstveno, izlažemo istorijsku pozadinu ove ideje i povezujemo je sa aktuelnim pitanjima u psihoterapiji. Nadalje, prikazujemo psihoterapija, relevantnu literaturu koja se fokusira na sličnosti i razlike u ishodima različitih modaliteta i razjašnjavamo prepoznate efektivne elemente psihoterapije kao što su efekti klijenta, terapeuta

efikasnost, Dodo presuda i njihove interakcije. Dodatno, diskutujemo o savremenim trendovima $u$ istraživanjima efikasnosti i postavljamo pitanja o prirodi teorije i prakse psihoterapije. Na kraju, dajemo kritiku, naglašavamo potencijalne probleme i nudimo različite perspektive o značaju i značenju Dodo pretpostavke koja se tiče terapijskih i van-terapijskih posledica i korelata. 


\section{Introduction}

In the last seventy years or so, the practice of psychotherapy has been under significant scrutiny, and has been a controversial subject for many researchers and practitioners to this day. Historically speaking, different themes were in focus of research and debate concerning this matter. The seminal work of Hans Eysenck (Eysenck, 1952) casts doubt on the overall usefulness of psychotherapy across modalities. He showed in his study that not only psychotherapy, both eclectic and psychodynamic was not useful, but a higher percentage of people got better from spontaneous remission than people who were subjected to psychotherapy. Picking on various problems in his methodology, many researchers disputed this idea and proven that psychotherapy indeed does work (Rosenzweig, 1954; Lambert \& Barley, 2001). The introduction of controlled clinical trials and metaanalyses in the 1970's solidified this idea of efficacy and effectiveness of psychotherapy (Smith \& Glass, 1977). From Eysenck's research up until now, not counting case studies, it seems that more than 12000 clinical trials and more than 700 meta-analyses have been performed, almost all with the same conclusion - psychotherapy is an empirically supported and evidence-based treatment, which has significant effects on psychological well-being (Wampold \& Imel, 2015). In effect, the research question shifted from "Does psychotherapy work?" to "What works in psychotherapy".

It would seem that looking at the sheer corpus of studies, this question would not be that hard to answer. In reality, looking at clinical trials, meta-analyses and component studies, considering non-scientific factors such as insurance policies, pharmacological houses, marketing, alongside data, as skewed, cherry-picked and contradictory at times, it would seem that different modalities have the same outcomes and are equally efficacious and effective (Luborsky et al., 2002). Enter the Dodo bird. In 1936, Saul Rosenzweig (Rosenzweig, 1936), hypothesized that different psychotherapeutic formats have the same outcomes. This idea to this day began to be known as the Dodo Bird verdict, a name inspired by the character in Alice in Wonderland who famously exclaimed - "Everybody has won and all must have prizes". This suitable metaphor has been used to elucidate that regardless of the theoretical underpinnings, the various psychotherapeutic interventions appear to be equally effective (Lambert \& Bergin, 1994). It is interesting that the discussion about what works in psychotherapy is older than the question does therapy work at all (Eysenck, 1952). The aforementioned idea has been successfully disputed, as was mentioned before, but the problem of efficacy and effectiveness correlates remained.

From its origins, different authors drew conclusions on what is working in psychotherapy. Some of the early notions were that hope is the key element in counselling (Snyder et al., 2000), psychological interpretation, catharsis and the therapist's personality, but also insight, and therapeutic relationship (Grencavage \& Norcross, 1990). It is also interesting that these common factors were not considered relevant, on the opposite, they were regarded as noise and confounding variables in first clinical trials and meta-analyses, again, reflecting on the relevance of the medical model perspective. It was only in the 1980's that these factors came into research focus (Norcross \& Greencavage, 1989). As it would be discussed below, commonalities, common factors, the placebo effect of psychotherapy or common agents of change, whatever the name historically was, are paramount in psychotherapy. If the Dodo verdict is true, several questions arise. Are there any differences in modalities whatsoever, what does that mean for our conceptual understanding of psychopathology, what is effective in psychotherapy, and, maybe the most important - is the Dodo conjecture beneficial or detrimental? Some of those questions will be addressed in the following pages.

\section{Ok, so what does research say?}

Out of the staggering amount of available literature, a good number of clinical trials, RCT's and meta-analyses were used to test the Dodo conjecture. The golden standard in the literature, it would seem, relates to several rules and limitations that seminal meta-analyses impose on themselves in testing the hypothesis. Namely, studies use the Cohen's d coefficient in order to compare sample and effect sizes (Siegel, 1997). Secondly, these studies usually test relative efficacy of pairs of psychotherapies, the rationale for that being the utility of testing active treatments and not treatment vs control, since the efficacy of treatments in comparison to TAU (treatment as usual) has been well documented (Lambert \& Bergin, 1994). Conversely, samples are easier to compare in the treatment - treatment condition because of the greater similarities of participants in light of the important variables. It would seem that most analyses used sets of two treatments to compare (Luborsky et al., 2002). Also, the literature suggests that the studies include mood 
disorders, and the disorders of the neurotic range the most (Luborsky et al., 2002).

To name a few, Berman, Miller, and Massman (1985) reported non-significant differences in cognitive therapy and desensitization from 20 studies, Robinson, Berman and Neimeyer (1990) suggested from their findings that cognitive behavioural treatment is more effective than behaviour treatment, both of them being more effective than general verbal exchange. This would be contradictory to the Dodo verdict, but when the researchers controlled the outcomes for therapeutic allegiance, phenomena which will be discussed in more detail, the significance drops to zero. A meta-analysis (Luborsky, Diguer, Luborsky, Singer, Dickter, \& Schmidt, 1993) found insignificant differences between dynamic and other psychotherapies, which would go in line with the conjecture. On the other hand, one group of researchers found significant differences in efficacy between dynamic and CBT, in favour of cognitive behavioural (Cohen's d was - .47), registered in 14 studies (Svartberg \& Stiles, 1991).

The seminal work of Luborsky and colleagues (Luborsky et al., 2002) included 17 meta-analyses and yielded the mean effect size of .20, which is not large and statistically non-significant. The exact same findings were obtained when comparing Cognitive Behavioural therapy (CBT) and Psychodynamic therapy. When the researchers corrected the estimates controlling for the therapeutic allegiance effect, the coefficient dropped to .12. To reiterate, it seems that the therapeutic allegiance effect is an important factor, as it has been well documented in studies, and research suggests that the correlation between this effect and the outcome is a staggering Pearson's r= .85 (Luborsky, Singer, \& Luborsky, 1975).

It is highly worth mentioning the work of Wampold and his associates (Wampold et al., 1997). The aim of their study was to examine the validity of the Dodo verdict, by improving some methodological and procedural issues. Namely, effect sizes were often derived from studies that did not directly compare therapies, the effects were evaluated by classifying treatments into categories and the treatments were not necessarily intended to be therapeutic. The researchers refined their study by comparing directly different modalities since the frequent rationale up until then was to compare effect sizes of treatments when compared to the control group. Also, they have dropped the idea of clustering modalities, because the conjecture should apply for all treatments and not groups, and they have used only bonafide treatments defined as ones which are based on psychological principles, offered viable treatments, contained specified components, and were delivered by professionals. They have found no significant differences in any effects registered (Wampold et al., 1997), and the effect size was identical to the Luborsky and colleagues' study from 1975 (Luborsky et al., 1975). Also, they have included the year of the publication of the incorporated studies as a variable, because they wanted to test out the hypothesis that in years, the methodology would be improved, showing more valid data. The results showed that the year of publication does not contribute to the effect size. Conversely, there are some studies which aimed at testing the effect of several factors that are necessary for specific treatments.

Ahn and Wampold (2001) conducted a meta-analysis of component studies and found that there is a non significant difference in outcomes depending a specific component is present or not, indicating that a concrete component is not needed for the therapeutic effect. Utility of specific treatments was also examined by contrasting effects, with or without the therapeutic manual. From the dominant reductionistic perspective, the adherence to the manual, i.e. confiding a session to a predefined schedule should be beneficial. The meta-analyses performed (Henry, Schacht, Strupp, Butler, \& Binder, 1993) showed an opposite effect. Namely, the adherence to the manual did not increase efficacy and was positively correlated with the deterioration of the therapeutic relationship in several included studies.

Results of the mentioned studies show very strong support for the Dodo verdict. Obviously, there is more than one explanation for these results. It well may be that one treatment is favoured by the researcher's positive allegiance in one study, and the negative allegiance in the other, cancelling the effect in general. Another explanation for these findings is the validity of the conjecture itself. In other words, it could be inferred that common factors, which are integral for all modalities, produce the effect, such as the therapeutic relationship, abreaction, selfunderstanding and improved cognitive meta- processes (Teasdale, Moore, Hayhurst, Pope, Williams, \& Segal, 2002), irrespective of the specific ingredients and interventions. Another explanation for these effects includes the problems that emerge from procedural difficulties and design limitations, such as representativeness of the measures for treatment processes and the statistical power of the findings (Howard, Krause, Sauders, \& Kopta, 1997). Finally, the interactions between participants 
personalities, beliefs about what works, and the types of psychopathological manifestations have not been considered, so, different therapies could have different in vivo, or in vitro outcomes, but under a "different strokes for different folks" assumption (Blatt, 1992).

It is also worth noting the remarks of Budd and Hughes (2009) concerning the validity of Randomized Controlled Trials (RCT's) in this domain. Namely, adhering to the reductionistic rationale, RCT's have innate assumptions which can skew the results. Unless controlled for, RCT's use homogenous groups diagnostically-wise which is not ecologically valid because of the high comorbidity between disorders, joint features, "fuzzy boundaries", etc. In other words, to paraphrase Stefanis (2008): "Psychotherapy modalities do not read the DSM". Secondly, the authors point out that treating type of therapy as an independent variable need not be well - founded. This is an argument which pertains to the difficulty separate and compare modalities clearly. It is commonly known that experienced therapists "borrow" techniques from different modalities more than not, which is an increasingly common practice (Gavrilov-Jerković, 2003). As noted in a different study (Elkin et al., 1989), proponents of Interpersonal therapy (IPT) conducted seances in such a manner, that they featured more components from Cognitive Behavioural Therapy than IPT. The third flawed assumption of RCT's in this domain is associated with a pull force towards a reductionistic perspective of the processes which govern, amongst other things, the onset, maintenance and treatment of mental disorders. In this analogy, psychotherapy is a "cure", and sessions are the "dose". As noted elsewhere (Borsboom \& Cramer, 2013), mental disorders do not behave like medical constructs, and thus, applying the same research logic is problematic and should be interpreted with caution.

\section{Ok, so what does work?}

The data is unequivocal - all treatments have won, and all must have prizes. The mounting evidence shows that the doctrine of specificity has been disputed. The change in psychotherapy derives from elements that transcend all approaches. Lambert and Bergin, (1994) reviewed extensive outcome literature and has demonstrated that four factors are agents of change. Based on their importance, they are the following - common factors, hope and expectancy, placebo effect and the models and techniques. Many authors, furthermore, speculate that the specific techniques are effective because of the expectancy and the competency of the therapist, and not because of the techniques per se. If the common factors are effective and important, what are they?

\section{The Alliance - Outcome Relationship}

This common factor is probably one of the most popular and it transcends all approaches. Over 1000 findings (Orlinsky, Ronnestad, \& Willutzki, 2004) reflected the power of this commonality. It is one of the best predictors of outcome, irrelevant of the length of the therapy (Horvath, 1994). Several meta-analyses demonstrated the importance of this factor. For example, Horvath and Symonds (1991) reviewed 20 studies and found a Cohen's $d$ of .54 which is considered a medium-sized effect. To put it into perspective, this effect counts for $7 \%$ of the outcome, while the differences between therapies, as elucidated by other studies counted for $1 \%$ of the effect. A review performed by a group of authors (Messer \& Wampold, 2002) found a smaller, $5 \%$ contribution of this factor in their study. In their meta-analyses, they have examined which commonalities are frequently marked by professionals and clients as important, or directly examined. When reviewing the literature on the matter, one must turn to the seminal work of Greancavage and Norcross (1990). In their study, they have found that a high percentage of studies endorsed the relationship as most important, but also engagement by the therapist and transference as the third most endorsed factor. It is to be noted that the research suggests that the evaluation of the relationship by the client is more important than evaluation of the therapist (Horvath, 1991).

\section{Therapist and Researcher Allegiance}

As noted before, this factor is one of the most potent, the literature suggests (Messer \& Wampold, 2002). In the traditional, medical model of mental disorders, the therapist's or researcher's belief in the efficacy of a given treatment should not matter, but research shows that the allegiance counts for $65 \%-70 \%$ of the differences in treatments, respectively (Luborsky et al., 2002; Wampold \& Imel, 2015). Conversely, some authors (e.g. Llewelyn, 1988) suggest that the interventions themselves are not as important as the client's interpretations of what said interventions mean and want to convey. The reader is encouraged to see Greancavage \& Norcross (1990) for more extensive review on this factor, since it would 
surface the scope of this paper if included here.

\section{Therapist Effects}

From the medical model perspective, the characteristics of the therapist should not make a significant contribution to outcome - it doesn't matter who treats you as long as they use the same (adequate) treatment. The research suggests that $6 \%$ - $9 \%$ of the outcome effect comes from the confidence of the therapist about the efficacy of his treatment (Messer \& Wampold, 2002). It is believed that, although it is not certain what exactly makes this effect, it seems that the more the therapist uses common factor, the better the outcome (Wampold \& Imel, 2015). The meta-analyses by the mentioned authors yielded 20 factors which appear to be relevant and frequent in their sample. The most frequent ones were general positive descriptors, a therapist who cultivates hope, warmth, and positive regard, empathy, and one of acceptance (Greancavage \& Norcross, 1990).

\section{Client Characteristics}

There have been many proposed qualities of the client that contribute to positive outcomes. It seems that the most important instance is hope and positive expectations as discussed before. One meta-analysis showed that in $26 \%$ of included studies this factor has been demarked as highly relevant (Greancavage \& Norcross, 1990). Aside from that, the same analyses showed that high distress correlated positively with the outcome because the patients feel better very soon after starting therapy. Close to that, the fact that patients actively seek help has been elucidated as an important factor because it taps into a very important agent of change - motivation (Greencavage \& Norcross, 1990).

\section{Change process}

What is helpful in the therapist - client exchange is probably the central question in the issue of the efficacy of psychotherapy. We turn again to the meta-analyses discussed above. Their review yielded 28 commonalities, included in every therapy, independent of the theoretical underpinnings that have been proven useful (Greencavage \& Norcross, 1990). The highest endorsed factors among the sample of studies were an opportunity for ventilation, acquisition of new behaviours, provision of rationale, insight, emotional learning, feedback, mastery and tension reduction (Greencavage \& Norcross, 1990).
Looking at these factors it is easy to conclude that all of these general mechanisms of change are integral for any therapeutic modality, which goes in line with the Dodo verdict conjecture.

The data suggests that the therapeutic relationship, the opportunity for catharsis, acquisition of new behaviours, hope, positive characteristics of the therapist and a provision of a rationale are the most important agents of change in therapy (Duncan, Miller, Wampold, \& Hubble, 2010). All of these factors are common to all modalities. Maybe the techniques which lead to these instances tend to vary, but the goal is the same. This completely goes in line with the central proposition - different therapies have the same positive outcomes. This has to be a positive and motivating finding, surely?

\section{Discussion}

Everybody has won and all must have prizes. This conjecture, alongside efficacy research, gives validity, not only to psychotherapy in general but also to various bonafide modalities in an equal manner. The idea that psychotherapy promotes well-being, irrespective of the modality has to be an encouraging proposition, for clients and professionals alike, surely? There are many authors who find this conjecture important and positive, but not everyone. For example, Rachman and Wilson (1980) found this idea unacceptable. For these and many other authors, the idea that irrelevant of the person, problem or therapy the same advice should be given is, to put it mildly, invalid. It could be speculated that this view elucidates a much more sinister and dark underlying process - everybody having prizes only enflamed the need to find the winners and losers. Both in theory, and in practice. In a sense, the Dodo bird was targeted in malice, even though it did not know it was in danger to begin with.

This is reflected in the position of the American Psychological Association when the task force proclaimed that there must be a winner, a therapy which targets specific instances which lead to better outcomes if it is going to even try to compete with biological psychiatry and its methods. The pressure to find the winner has been seen in the attitude of the US Food and Drug Administration as well, which, to paraphrase, exclaimed that only medical treatments should be administered because no psychotherapy can elucidate the right ingredients in therapy in comparison to other modalities. Moreover, the race to adhere to the 
insurance policy makers who pick out the most effective one for their programs has initiated a "turf war" between therapies, in which the Dodo is a "thorn in the eye" for many. Conversely, it would seem that this race to find a unified, procedurally strict treatment for all clients plucks away (no pun intended) the therapeutic variety and "tailor made" approaches, thus undermining the idiosyncrasies of therapists and clients alike. By insisting that one modality has to have the high ground, we are implicitly inferring that there is a distinct, or technically speaking, unifactorial relation between therapeutic techniques and positive effects. Theory and practice certainly suggest that this is not the case. Having in mind the multifactorial, situationally and culturallyladen context in which mental health issues emerge, can we claim that the same problem can be solved by one single approach? If there is a modality which should be endorsed, as suggested by the guidelines, is the client deprived of the opportunity to choose which approach is the best for him? Drawing a parallel between physical and mental health, if the exercise choice is important for motivational and adherence reasons, why can not one choose between different psychotherapy modalities? If in other areas we often see diversity as an advantage, is it good or bad to reduce the therapy to one single modality?

We can only speculate that CBT advocates (present company included) do not agree with the conjecture more because this modality values structure, specific interventions to specific phenomena the most, in comparison to psychodynamic and humanistic therapies. It is certainly more compatible with the dominant medical (-ish) model. It would be impertinent and wrong to make a clear-cut distinction on the matter, but, as Italians would say - "Se non è vero, è ben trovato" (It is not true, but (maybe) well-conceived). The dispute, especially when it comes to finances, skews empirical findings, puts forth pride (and prejudice), and increases professional hermeticism, everything detrimental to the improvement of the profession. Where does that leave us? Professionals, who are not directly involved in these extra-professional disputes?

One could ask "Is the Dodo verdict a good or a bad thing?". On one hand, the well - being of the client is the paramount goal, so the aggregate effect of therapy regardless of its specific components should be welcomed. However, is there a more latent, private, intimate perception about the effectiveness of different modalities, be it for personal, professional or utilitarian reasons? Are we completely derived of professional pride, self-perceived competence and belief in our understanding of what is really going on? Are we selfdeluding ourselves about the validity of our understanding of the nature client's problems? Is the accumulation of knowledge and expertise only in the service of being able to persuade the clients more confidently? Are we at peace with the "different strokes for different folks" perspective, provided that different folks have same problems? Should we keep this equality of efficacy as a trade secret? If the clients profit from therapy should it even matter? As Bertolt Brecht would wonderfully put it "What is robbing a bank in comparison to opening a new one?" On the subject of "new ones", the terminological chaos has led to a interesting period where at the same time, number of modalities rise, but the proponents of said modalities strongly insure the public that all treatments target similar aspects of functioning (hence the usefulness of common factors), simultaneously criticizing a modality for its shortcomings. Example of this would be criticizing CBT for its depth of analysis and exclaiming that their therapy is effective as CBT. On the subject of banks, from our perspective, it seems that the Dodo conjecture is most certainly important and fundamentally beneficial. Unfortunately, the matter of therapy efficacy is rarely about where, when, with whom, and what works. It is more than often a matter of how to industrialize therapy, and how to sell your product (some advertise as selling oneself?!). And my, how easy it is to convince clients that your product is the best, knowing the Dodo notion, and having a bit of charm. As Charlton (in Budd \& Hughes, 2009) notes, scientific knowledge should be sometimes explored as an open discourse between different perspectives rather than exploring the results of empirical studies which is pertinent to this notion. Even though this approach had an immense impact in psychological science, this notion can have some unfavourable emerging issues in this domain. If treatments have similar outcomes, and the mechanisms of change are not clear, that paints the way of potential misconduct by extra-professional practitioners. The emergence of pseudo - scientific or non - scientific treatments could be, partly, understood from this context in which people indeed do need and expect help, and practitioners who are willing to oblige counting on the beneficial effects of general factors. As Gavrilov-Jerković noted (2003) there has been a sizeable influx of modalities which focus on commonalities of different mental health issues (e.g. demoralisation) inspired by pre psychological approaches, such as spirituality. We agree that the ailments many people share must be explored in 
the therapy session, extensively. However, a conceptual matter arises - is the validity and utility of common factors different between different treatments, and/or bonafide treatments and pseudo - scientific treatments? If that is the case, there is a specific component in the use of common factors which makes them specific in a given sense. Which brings us back to the beginning. Moreover, it would seem that the confounding opinions in professional and extra-professional domains either gravitate towards exclusivity of a given modality, or bringing all approaches on equal grounds. It is rarely, however, examined why these general mechanisms of change work. To add to the aforementioned, not only there is an aspect of specificity of general factors, but also the context in which they are conveyed. If the potency of specific factors varies across multidimensional contexts (for example a therapist vs a life coach vs a layman) it can be argued that the effect difference is due to specificity. Which can and is empirically under investigation. The Dodo is extremely important, but paradoxical in nature. If non - specific factors are under scrutiny and broken down into components, do they become specific factors in a sense, independent of clients or therapists? If we do not regard common factors as artefacts anymore, and bring them to research focus, will they be subjected to the same positivistic empirical treatment?

If the first "insult" to psychology was Kant with the mindbody dualism, Freud being the second with his animalistic understanding of human nature, this (in)famous bird is the third. The fact (and it can be called a fact) that non-specific factors fundamentally contribute more to therapy outcomes directly suggests that a revision of our understanding of psychopathology theory, practice and their integration is needed. Relying on the reductionistic models has come to collect. Big time. The fact that theoretical perspectives cannot transpose concrete specific factors with significant effects to therapy is worrisome. Gavrilov-Jerković (2003) rightly notes, the relation between theory and empirical evidence is analogous to a dysfunctional marriage, where the clinical practice would be the maladapted adoptee (the reference writes itself here), in the messiness around the questions of empirical results, phenomena conceptualisation and clinical utility.

Is the Dodo bird a Jedi or a Sith? We cannot answer that question conclusively. It would be interesting to juxtapose a popular Star Wars character Kylo Ren as the personification of this problem. A villain, or even better an "anti-hero", with formidable destructive prowess, who also has the opportunity, and maybe the intent, to silence the Dark Side from the inside and restore balance. Same is expected from research and psychotherapy. In the end, it doesn't matter if the Dodo is a Jedi or a Sith. What matters is that there is a disturbance in the force, and a New Hope is more than needed.

\section{IZJAVA}

Autori su svojim izjavama potvrdili nepostojanje bilo kakvog sukoba interesa.

\section{LITERATURA}

Ahn, H. N., \& Wampold, B. E. (2001). Where oh where are the specific ingredients? A meta-analysis of component studies in counseling and psychotherapy. Journal of Counseling Psychology, 48(3), 251.

Berman, J. S., Miller, R. C., \& Massman, P. J. (1985). Cognitive therapy versus systematic desensitization: Is one treatment superior? Psychological Bulletin, 97(3), 451.

Blatt, S. J., \& Maroudas, C. (1992). Convergences among psychoanalytic and cognitive-behavioral theories of depression. Psychoanalytic psychology, 9(2), 157.

Borsboom, D., \& Cramer, A. O. (2013). Network analysis: an integrative approach to the structure of psychopathology. Annual review of clinical psychology, 9, 91-121.

Budd, R., \& Hughes, I. (2009). The Dodo Bird Verdict - controversial, inevitable and important: a commentary on 30 years of meta-analyses. Clinical Psychology \& Psychotherapy: An International Journal of Theory \& Practice, 16(6), 510-522.

Duncan, B. L., Miller, S. D., Wampold, B. E., \& Hubble, M. A. (2010). The heart and soul of change: Delivering what works in therapy. American Psychological Association.

Elkin, I., Shea, M. T., Watkins, J. T., Imber, S. D., Sotsky, S. M., Collins, J. F., ... \& Fiester, S. J. (1989). National Institute of Mental Health treatment of depression collaborative research program: General effectiveness of treatments. Archives of general psychiatry, 46(11), 971-982.

Eysenck, H. J. (1952). The effects of psychotherapy: an evaluation. Journal of consulting psychology, 16(5), 319.

Gavrilov-Jerković, V. (2003). Modern tendencies in psychotherapy: The specialisation of practice and knowledge integration. Psihologija, 36(1), 7-38.

Grencavage, L. M., \& Norcross, J. C. (1990). Where are the commonalities among the therapeutic common factors? Professional Psychology: Research and Practice, 21(5), 372.

Henry, W. P., Schacht, T. E., Strupp, H. H., Butler, S. F., \& Binder, J. L. (1993). Effects of training in time-limited dynamic psychotherapy: Mediators of therapists' responses to training. Journal of consulting and clinical psychology, 61(3), 441. 
Horvath, A. O. (1994). Research on the alliance. The working alliance: Theory, research, and practice, 259-286.

Horvath, A. O., \& Symonds, B. D. (1991). Relation between working alliance and outcome in psychotherapy: A meta-analysis. Journal of Counseling Psychology, 38(2), 139-149. http:// dx.doi.org/10.1037/0022-0167.38.2.139

Howard, K. I., Krause, M. S., Saunders, S. M., \& Kopta, S. M. (1997). Trials and tribulations in the meta-analysis of treatment differences: Comment on Wampold et al. Psychological Bulletin, 122(3), 221-225. http://dx.doi.org/10.1037/00332909.122.3.221

Lambert, M. J., \& Barley, D. E. (2001). Research summary on the therapeutic relationship and psychotherapy outcome. Psychotherapy: Theory, research, practice, training, 38(4), 357.

Lambert, M. J., \& Bergin, A. E. (1994). The effectiveness of psychotherapy. Handbook of psychotherapy and behavior change, 4, 143-189.

Luborsky, L., Diguer, L., Luborsky, E., Singer, B., Dickter, D., \& Schmidt, K. A. (1993). The efficacy of dynamic psychotherapies: Is it true that" everyone has won and all must have prizes?". In N. E. Miller, L. Luborsky, J. P. Barber, \& J. P. Docherty (Eds.), Psychodynamic treatment research: A handbook for clinical practice (pp. 497516). New York, NY, US: Basic Books.

Luborsky, L., Rosenthal, R., Diguer, L., Andrusyna, T. P., Berman, J. S., Levitt, J. T., Seligman, D. A. \& Krause, E. D. (2002). The dodo bird verdict is alive and well - mostly. Clinical Psychology: Science and Practice, 9(1), 2-12.

Luborsky, L., Singer, B., \& Luborsky, L. (1975). Comparative studies of psychotherapies: is it true that everyone has won and all must have prizes?. Archives of general psychiatry, 32(8), 995-1008.

Messer, S. B., \& Wampold, B. E. (2002). Let's face facts: Common factors are more potent than specific therapy ingredients. Clinical Psychology: Science and Practice, 9(1), 21-25.

Norcross, J. C., \& Grencavage, L. M. (1989). Eclecticism and integration in counselling and psychotherapy: Major themes and obstacle. British Journal of Guidance \& Counselling, 17(3), 227-247.

Orlinsky, D. E., Ronnestad, M. H., \& Willutzki, U. (2004). Process and Outcome in Psychotherapy. In MJ Lambert (Ed.) Bergin and Garfield's Handbook of Psychotherapy and Behavior Change (pp. 307-389).

Rachman, S., \& Wilson, G. T. (1980). The effects of psychological therapy (Vol. 24). Pergamon.

Robinson, L. A., Berman, J. S., \& Neimeyer, R. A. (1990). Psychotherapy for the treatment of depression: a comprehensive review of controlled outcome research. Psychological bulletin, 108(1), 30.

Rosenzweig, S. (1936). Some implicit common factors in diverse methods of psychotherapy. American journal of Orthopsychiatry, 6(3), 412.

Rosenzweig, S. (1954). A transvaluation of psychotherapy: a reply to Hans Eysenck. The Journal of Abnormal and Social Psychology, 49(2), 298-304. http://dx.doi.org/10.1037/h0061172

Siegel, D. J. (1997). Memory, trauma, and psychotherapy. The handbook of infant, child, and adolescent psychotherapy, 2, 221-277.
Smith, M. L., \& Glass, G. V. (1977). Meta-analysis of psychotherapy outcome studies. American psychologist, 32(9), 752-760.

Snyder, C. R., Ilardi, S. S., Cheavens, J., Michael, S. T., Yamhure, L., \& Sympson, S. (2000). The role of hope in cognitive-behavior therapies. Cognitive therapy and Research, 24(6), 747-762.

Stefanis, N. (2008). Genes do not read DSM-IV: implications for psychosis classification. Annals of General Psychiatry, 7(1), S68.

Svartberg, M., \& Stiles, T. C. (1991). Comparative effects of shortterm psychodynamic psychotherapy: a meta-analysis. Journal of consulting and clinical psychology, 59(5), 704-14.

Task Force on Promotion and Dissemination of Psychological Procedures. (1995). Training in and dissemination of empirically-validated psychological treatment: Report and recommendations. The Clinical Psychologist, 48, 2-23.

Teasdale, J. D., Moore, R. G., Hayhurst, H., Pope, M., Williams, S., \& Segal, Z. V. (2002). Metacognitive awareness and prevention of relapse in depression: empirical evidence. Journal of consulting and clinical psychology, 70(2), 275.

Wampold, B. E., \& Imel, Z. E. (2015). The great psychotherapy debate: The evidence for what makes psychotherapy work. Routledge.

Wampold, B. E., Mondin, G. W., Moody, M., Stich, F., Benson, K., \& Ahn, H. N. (1997). A meta-analysis of outcome studies comparing bona fide psychotherapies: Empiricially, "all must have prizes.". Psychological bulletin, 122(3),203.

Datum prijave: 07.06.2018.

Datum prihvatanja: 09.10.2018.

\section{Kontakt}

Radomir Belopavlović, University of Novi Sad, Faculty of Philosophy,

Dr Zorana Đinđića 2, Novi Sad

radomirbelopavlovic@gmail.com

Tanja Petrović, University of Novi Sad,

Faculty of Philosophy,

Dr Zorana Đinđića 2, Novi Sad

boskovictanja1@gmail.com

Snežana Tovilović, University of Novi Sad,

Faculty of Philosophy,

Dr Zorana Đinđića 2, Novi Sad

tovilovics@gmail.com 